\title{
Home Made Pneumatic Otoscopy
}

\author{
Kamal F. Akl
}

Received: 20 March 2011 / Accepted: 27 September 2011 /Published online: 8 October 2011

(C) Dr. K C Chaudhuri Foundation 2011

Sir,

The presence of eustachian tube dysfunction may lead to the accumulation of sterile fluid behind the tympanic membrane. The fluid may get infected in the presence of persistent negative middle ear pressure. Decreased mobility of the tympanic membrane may signify the presence of otitis media with effusion (OME). The gold standard for the diagnosis of OME remains to be pneumatic otoscopy [1-3].

Jones and Kaleida demonstrated the accuracy and importance of pneumatic otoscopy, by using a video otoendoscopic test, in the diagnosis of OME [1]. Unfortunately, pneumatic otoscopy is underused by some pediatricians.

We improvised a simple replacement for the pneumatic otoscope (Fig. 1). All that is needed is a $10 \mathrm{ml}$ disposable syringe (A), 20-25 $\mathrm{cm}$ piece of an intravenous fluid line (B), a plastic adaptor (in our case, it was part of a ball point pen refill), (c) and of course an otoscope (D). Positive and negative pressure may be applied by aspirating and injecting air simultaneously. A good seal is demonstrated by testing for negative pressure against a fingertip. The procedure is safe, and inexpensive.

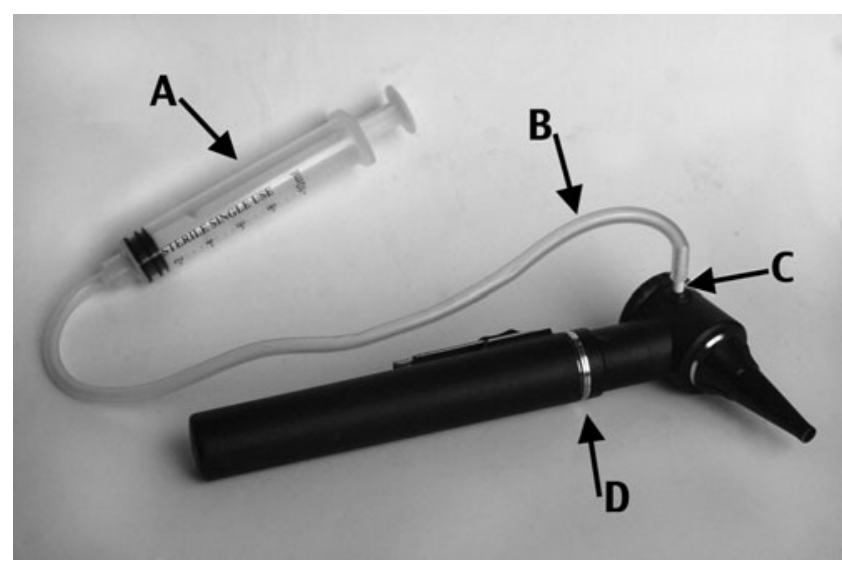

Fig. 1 Constituents of home made pneumatic otoscopy A syringe B connecting tube $\mathbf{C}$ plastic adapter $\mathbf{D}$ otoscope with side hole

\section{References}

1. Jones WS, Kaleida PH. How helpful is pneumatic otoscopy in improving diagnostic accuracy. Pediatrics. 2003;112:510-3.

2. Pinchichero ME. Acute otitis media: Part I. Improving diagnostic Accuracy. Am Fam Physician. 2000;61:2051-6.

3. Pelton SO. Otoscopy for the diagnosis of otitis media. Pediatr Infect Dis J. 1998;17:540-3.
K. F. Akl $(\bowtie)$

Department of Pediatrics Jordan University Hospital,

University of Jordan,

PO Box 831373, Amman 11183, Jordan

e-mail: kachbl@yahoo.com 